\title{
Research on the Value of Classical Italian Art Songs for Vocal Music Learning
}

\author{
Wang Huizhong \\ Nanyang Institute of Technology, Nanyang, China \\ 1956452532@qq.com
}

Keywords: Classical Italian songs, Vocal music learning, Guidance and reference

\begin{abstract}
The content of classic Italian works of art is rich and varied. The songs are short, the melody lines are smooth, full of lyrical, the sound range is not wide, the contrast between strong and weak is obvious, and the rhythm is rhythmic. These characteristics are all for improving singing skills and effective breathing training. Through its study, we have truly understood the concept of a wonderful voice and sound, and at the same time, we have also developed a good singing habit. This paper elaborates on the four aspects of the development of classical Italian art songs, the style of art, the value of vocal learning, and its application. This will enable learners to establish correct singing awareness and status through learning these works, know how to learn vocal music works, and develop earnest and rigorous learning attitudes. Through his continuous singing, the singer's ability to understand the music is enhanced, so that his inner feelings are rich and his life experience is enriched, and his own music cultivation and cultural cultivation are improved. Therefore, classical Italian art songs are indispensable classics in the process of learning science bee singing.
\end{abstract}

\section{Introduction}

Classical Italian art songs originated in the first half of the 17th and 18th centuries. The birth of operas resulted in the production of melody-based vocal music. It was produced by the Italian Renaissance movement, and was promoted by the Renaissance [1]. "Ism" has a close relationship. In response to the dark church rule in the Middle Ages, the liberation of the authority of divine authority and the control of all religion-dominated churches, the Renaissance proposed the "humanism" ideology. This ideology focuses on people's lives and their love of life. Under the influence of the "humanism" ideological trend, the continuous development and innovation of the music art not only adopted the "digital bass" universally, but also appeared a harmony system based mainly on the size and tone, and the polyphonic music and the harmony had reached a perfect combination [2]. Transferring to the main texture, classical Italian art songs were born and developed during this period. The work has produced heartfelt praise and praise for pure love and beautiful nature. Although some works still involve religious themes, the content has slowly transformed from the initial manifestation of God to a humanized "god", which is a great improvement [3]. At the same time, the portrayal of the character's inner activities and the beauty of the future are also one of the eternal themes of Italian opera.

\section{The Artistic Style of Classical Italian Art Songs}

In the seventeenth and eighteenth centuries, both instrumental music and vocal music not only inherited the outstanding achievements of the Renaissance, but also played a very important role in the later romantic style. Classical Italian art songs reflect the typical style characteristics of various important opera genres at the time, combining the grand and rhythmic character of the Baroque period with the simple and simple artistic style of the Renaissance. The content of the work is extensive, the subject matter is varied, and the melody of the main texture is adopted in the music writing. The content of the lyrics reflects the humanistic trend of thought during the Renaissance [4]. At the same time, it is skillfully combined with the melody, the rhythm of the technique is varied, and the decorative tone is used widely [5-6]. These characteristics make the classical Italian art work become the teaching material commonly used in vocal learning in China and even in the 
world, and it is also an indispensable classic in the process of learning the singing style of the bel kind singing method, as shown in Figure 1.

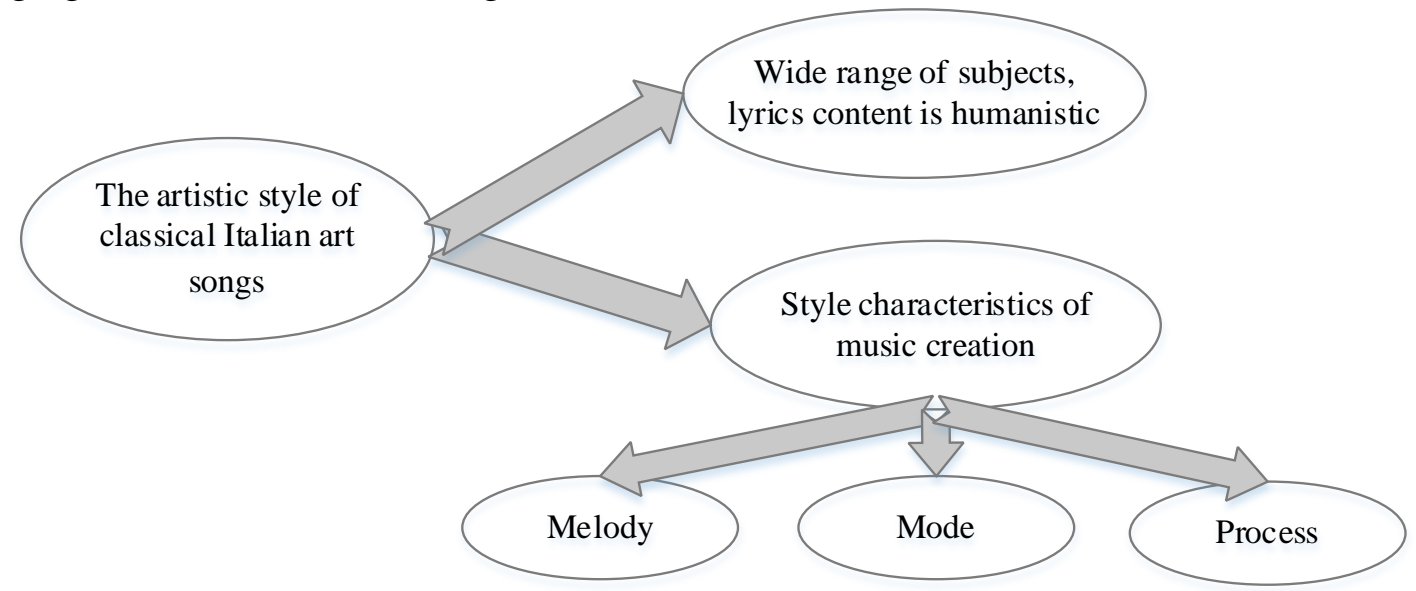

Figure 1. The artistic style of classical Italian art songs

Wide Range of Subjects, Lyrics Content is Humanistic. Classical Italian art songs are characterized by a wide range of subject matter and rich content. From the general direction, there are religious and secular themes. The subdivision includes Greek and Roman myths. The lyrics of classical Italian art songs are very humanistic. It has the emotional characteristics of "humanism" advocated during the Renaissance. The content expresses people's love for life, daringly extols beautiful nature and pure love, emphasizing the human heart's activities and the direct expression of emotions, and imagining and embarrassing the future or the desire for goodness.

Style Characteristics of Music Creation. The classical Italian art song music is simple and elegant in style, without complicated emotional changes and dramatic plot development. The calm and elegant, fresh and smooth features displayed make the audience easy to accept and suitable for beginners to learn and sing. From the melody, mode of use and accompaniment of classical Italian art songs, the style of music creation in this period are analyzed below:

In terms of melody, the early Italian vocal music was beautifully melodic, fresh and natural, with delicate and delicate emotions. It focused more on its overall orientation and layout. Most of the notes were between the progressive and the progressive, with little ups and downs, few beats, and generally no more musical range. Two octaves, the melody of this period is known for its softness and smoothness, and it is deeply loved by the audience.

In the use of mode, early Italian vocal music works began to use large and small. The different styles directly affect the mood and emotional color of the song, the major tone is suitable for expressing bright and cheerful music content, and the minor tone has a very good effect on expressing melancholy and dim music content.

In the singing process, the role of accompaniment can not be ignored. It can not only enhance the rhythm of rhythm, but also can quickly make the singer into a good singing state, into the music context. In this period of classical Italian art songs, accompaniment instruments are mainly used for organ or harpsichord.

\section{The Value of Classical Italian Art Songs in Vocal Learning}

The value of classical Italian art songs in vocal learning are divided into three aspects which are shown in Figure 2. 


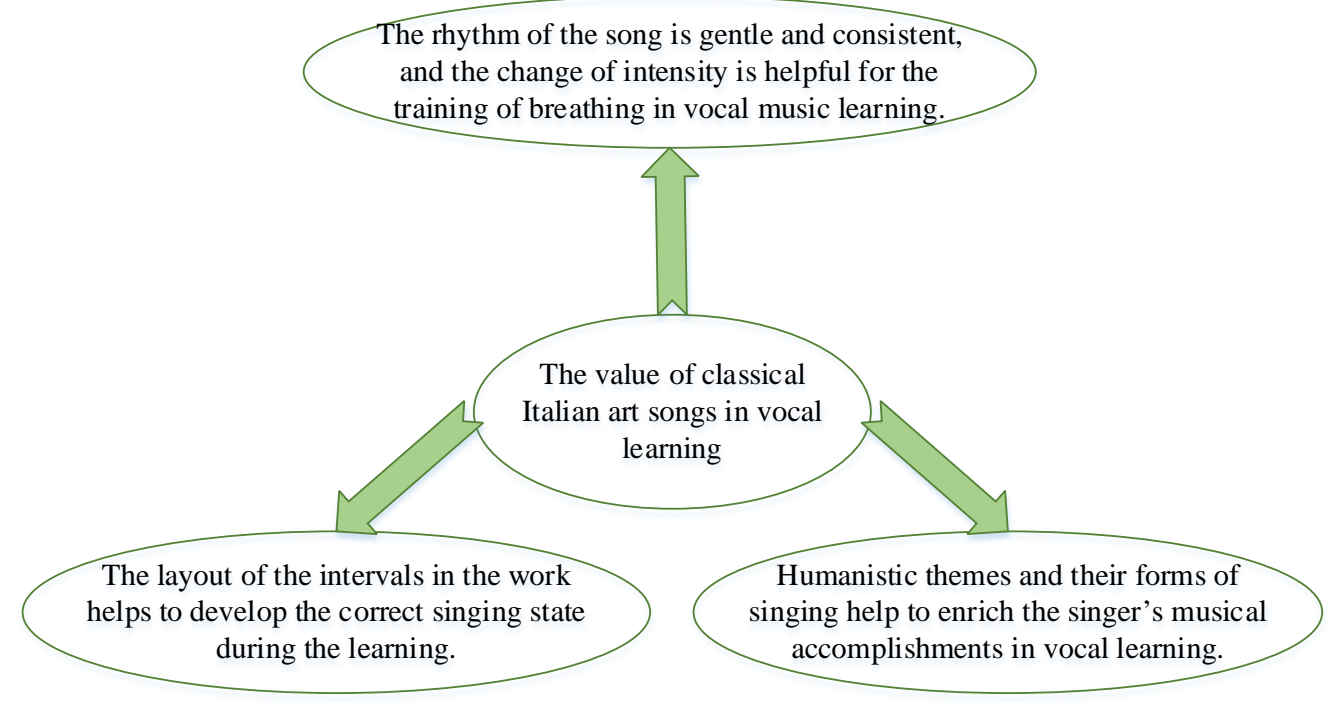

Figure 2. The value of classical Italian art songs in vocal learning

The Rhythm of the Song is Gentle and Consistent, and the Change of Intensity is Helpful for the Training of Breathing in Vocal Music Learning. Breathing is the basis for the use of vocal skills, and it is the premise to obtain a coherent and full sound quality. It is considered to be the most fundamental and critical element in belle singing art. Singing makes the respiratory organs get exercised. Because after years and even decades of continuous training and proper use, the breathing muscles are continuously enhanced, and the singers' ability to control them is further developed. Due to its unique artistic style, classical Italian art songs allow beginners to learn to use the breath and can accurately use it for singing.

Classical Italian works of art are based on the theme of love. The artistic style is pure and introverted, showing soft and delicate stretch and demure temperament. At the same time, the song structure is structured, short and compact, and the range is not wide. There is neither strong bass nor powerful treble. The melody lines are clear, and the notes are smooth and consistent. It is the best practice to develop the voice of the sound zone and maintain the stability of the air. The coherent and clear melodic lines require sounds to be issued with the support of a good atmosphere. Therefore, certain works of this period can be used as training vocals for long-term training.

The Layout of the Intervals in the Work Helps to Develop the Correct Singing State during the Learning. The arrangement of the intervals in the work includes the melody trend, the 3-5th arpeggio, the homophonic reverberated interval relationship, and the singing of decorative sounds. The following four aspects elaborate:

The melodic melody direction (up and down scales) makes the sound coherent, which is conducive to the unity of the vowels when the beginners sing. The upward melody, especially the swiftness of upward octave scales, will cause people to have a tense mood, avoiding the upward "stepping" state of the breath along with the height of the sound, and maintaining the singing state and function when singing in the low sound area. It feels that as the height of the sound increases its speed, it balances the sound and the sound.

The practice of three or five degrees of arpeggios or an octave within the octave has played an important role in extending the range and enhancing the flexibility of the sound. The increase in the number of tones brings invisible pressure to the singer, which in turn causes the breath to rise and the state of the cavity to be destroyed, affecting the unification of sound position and tone.

The homophonic repetition or the surround-type interval relationship refers to the mutual conversion of different vowels at the same pitch, which requires that the vowel sounds remain uniform while making corresponding strength changes, which is conducive to students based on the unified timbre Strengthen the ability to handle strong and weak changes. If the same pitch is expressed with the same intensity, the music sounds dull and lifeless.

The decorative sound is the basis of the training of flower cavity technology. For the singer, 
practicing the decorative sound can effectively enhance the flexibility and lightness of the sound. The technique of flower cavity was considered as an important criterion for measuring a good singer during this period. The singers decorate the work improvisationally according to the simple melody outline, creating a passionate and stimulating stage effect, so as to win the audience's applause and pursuit to win their artistic status. In the classical Italian art songs, the decorative writing techniques are relatively simple. The content of the lyrics determines the position of the decorations. Each of the songs requires light, natural, clear and legible sounds, and they are connected with the melody of the songs.

Humanistic Themes and their Forms of Singing Help to Enrich the Singer's Musical Accomplishments in Vocal Learning. Music cultivation is reflected in the singer's ability to understand music, ability to grasp the style of the work, aesthetic ability, and ability to appreciate music. Classical Italian vocal works are known for their beautiful melody and simple musical style. Practice of this period of work can not only train the vocalist's vocal skills in many aspects, but also help the singer to establish correct breathing and pronunciation and enhance the breath. The control ability and the sensitivity to the rhythm enhance the singer's pitch pitch, better control and sing the work.

The 17th and 18th centuries were an era that connected with the past, inherited the outstanding achievements of the Renaissance and also inherited the advanced ideas of the music art. Therefore, the vocal music works of this period have a wide range of topics and rich content. The lyrics in the works pursue the development of human nature and the expression of emotions. Composers adopt the concept of "humanism" as the core, and permeate them into music creation, subject matter, and style characteristics. Classical Italian art songs, with solo and piano accompaniment as the main forms of singing, played a very important role in improving the singer's overall musical quality. However, musical instrument manufacturing techniques and instrumental organizing techniques are not yet mature during this period. The vocal accompaniment textures are very simple. Many singers do not attach importance to cooperation with piano accompaniment, and feel that the accompaniment is in a subordinate position. We do not know the simple accompaniment of this period. The body creates a beautiful musical mood that can deepen the singer's understanding of the works' emotions.

\section{The Application of Classical Italian Art Songs in Vocal Music Learning}

The application of classical Italian art songs in vocal music learning are divided into three directions which are shown in Figure 3.

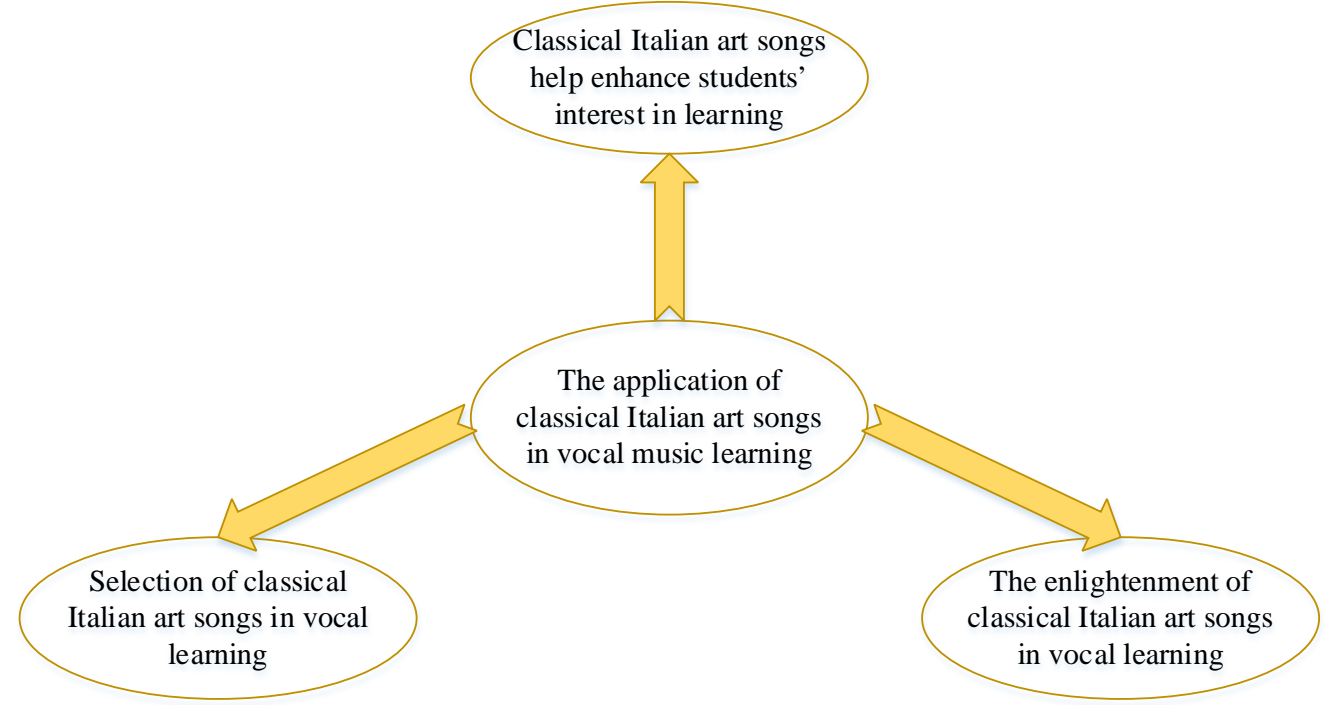

Figure 3. The application of classical Italian art songs in vocal music learning 
Classical Italian Art Songs Help Enhance Students' Interest in Learning. There are many kinds of difficulty and format in classical Italian vocal music. According to the students' interests and hobbies, they can choose to sing different styles of works. Students interested in vocal music will learn from them. By practicing vocal singing skills, you can listen to music of different types and styles and feel the artistic charm and fun of vocal music. Most of the classical Italian art song range is concentrated in the middle vocal area. There is no strong treble and strong bass. It is suitable for beginners to learn and sing. At the same time, the melody is beautiful, the rhythm is sharp, the phrase is short and clear, and the musical structure is simple. The learning of it is conducive to the unification of the training area for beginners, the use of breath, and the cultivation of the correct singing state. Complete singing works will increase students' curiosity and interest in vocal music, and ultimately increase their confidence in learning vocal music.

Selection of Classical Italian Art Songs in Vocal Learning. Italian vocal works have the most singing language and the most melodic and lyrical melody lines, as well as simple and clear structures, and are the most suitable songs for beginners to sing. If a beginner can fully grasp the vocalization method of the Italian language, singing style and singing skills of the bel canto, it is easier to sing. Therefore, the choice of tracks in vocal learning is very important. The selection of the track should be based on its own performance and technical level, and it is necessary to select targeted works. At the same time, we follow the principle of "deep into the deep" and from easy to difficult, with our own tone, vocal range, expressiveness, and technical ability to control as the starting point for targeted selection and practice.

The Enlightenment of Classical Italian Art Songs in Vocal Learning. Classical Italian art songs can effectively improve students' singing ability. Through the study of classical Italian art songs, students have mastered the correct breathing methods and basic singing skills. After this stage, the training of sounds in the Zhongsheng District has been continuously strengthened, so that the sound in the Zhongsheng District has achieved a good play. At the same time, it has mastered the skills of natural transitional high and low sound change areas, and the sound performance is consistent and flexible. At the same time, because the lyrics of the works are subtle, refined, and elegant, the songs should be played with special emphasis on stress, skipping, pauses, etc., focusing on the combination of lyric rhythms and melody mobility, and focusing on the connotation of the works. It makes sense for each note to live alive. This is what the singer demands during this special period.

\section{Conclusion}

The development of the vocal art culture in each period has brought endless joy to human beings, and has promoted the progress of vocal music and techniques, leaving us with valuable experience and a rich source of knowledge. Classical Italian art songs, with its own unique artistic style and exquisite vocal singing skills, make it occupy the most fundamental and most important position in the history of Bel Canto. This is undoubtedly a monument in the history of vocal music. And singing has had a profound effect.

For the overall situation we are learning now, the resources for learning are limited. The current repertoire is only representative of some composers. At the same time, the pertinence of learning is not strong. The students' understanding of the style and creative characteristics of a specific composer is not clear, let alone the improvement of vocal techniques. Therefore, current vocal learning should learn from the strengths of classical Italian art song learning, pay attention to details and basic skills training, perseverance. Advocating nature and using the works of this period effectively will bring some help to beginners.

\section{References}

[1] Li Wei. The Value of Italian Art Songs in Vocal Music Teaching[J]. Journal of Xingtai University, 2011, 26(3): 143-144. 
[2] Li Mingyue. Study on the Teaching Value of Italian Art Songs [J]. Journal of Changchun Normal University, 2016, 6: 104-106.

[3] Pang Jiahui. The Important Role of Classical Italian Art Songs in Vocal Music Teaching [J]. Journal of Liaoning Higher Vocational, 2012, 5: 87-88.

[4] Jia Juanjuan. The Singing Features of Italian Art Songs in Classical Period [J]. Big stage, 2015, 4: 113-114.

[5] Chen Guo. The Importance of Italian Art Songs in Vocal Music Teaching [J]. Journal of Suzhou College of Education, 2000, 4: 70-71.

[6] Xu Xin. The Role of Italian Classical Art Songs in Vocal Music Teaching [J]. Art Science and Technology, 2015, 11: 50. 